\title{
Caribbean sea-fan mortalities
}

SIR - Epizootics resulting in mass mortalities of Caribbean sea fans have been observed for more than 15 years, but the cause has remained unresolved ${ }^{1-3}$. Here we report for the first time the presence of a putative pathogen associated with diseased sea-fan tissue throughout the Caribbean.

We obtained samples of healthy and diseased Gorgonia ventalina and G. flabellum (Cnidaria: Gorgoniidae) from the Bahamas, the British Virgin Islands, Curacao, Saba and Trinidad ${ }^{4}$. We examined
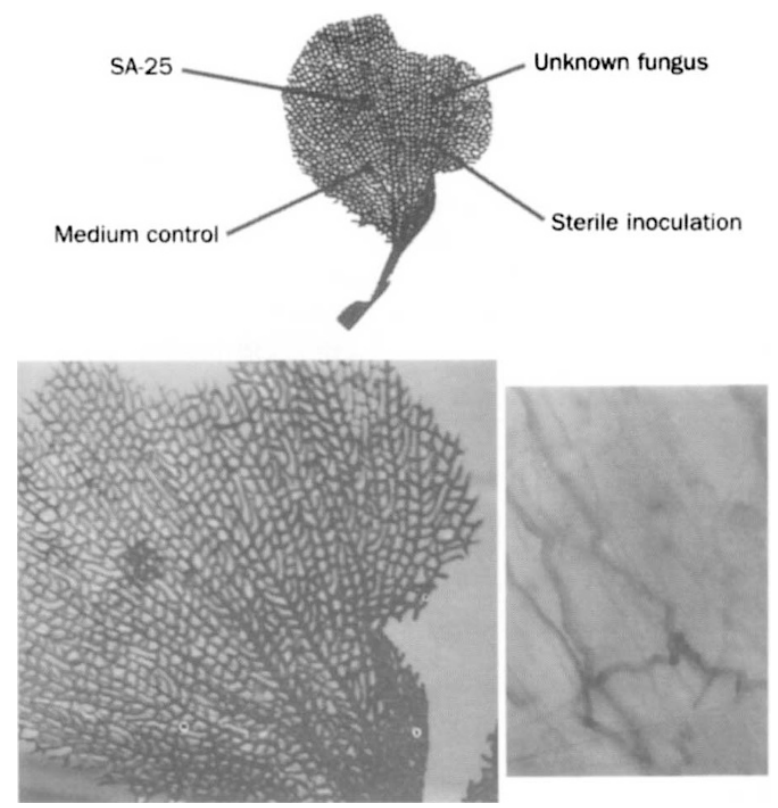

Sea-fan inoculation experiment. Top, sea fan inoculated with the putative pathogen SA-25, an unknown sea fan fungus, HE medium (on which SA-25 was grown) and a sterile inoculation. Bottom left, lesion produced by SA-25. Bottom right, micrograph of receding rind from the lesion showing fungal hyphae.

samples preserved in ethanol (80-100\%) under the microscope. Diseased samples showed distinct recession of rind tissue (coenenchyme, the outer organic rich matrix containing the living polyps), exposing the axial skeleton (dead central core). The exposed core was often colonized with a cyanobacterium similar to Phormidium corallyticum, the organism responsible for black-band disease in hard corals $^{5}$. Although this colonization of the core on some samples was extensive, it appeared secondary to the recession caused by the fungus. In all diseased samples, we observed hyphae embedded in the receding edge of the rind. Hyphae were not seen in healthy rind tissue.

We compared bacterial and fungal isolates obtained from healthy and diseased samples from each site after subculturing on similar media (reciprocal plating). Based on colony and cellular morphology, only one type of fungus was common to all diseased tissue. Microscopic observations of pure cultures grown on Hektoen Enteric agar (HE, Difco), supplemented with artificial sea water, showed the presence of conidiophores similar to those produced by the genus Aspergillus $^{6}$.

We used one of these isolates, SA-25 (from Saba), as an inoculum onto healthy G. ventalina (from San Salvador, Bahamas) in aquaria. Within 3 days, the area inoculated with SA-25 showed symptoms of the disease (recession of the rind, see figure). Microscopic observation of affected tissue showed abundant hyphal growth at the edge of the receding rind. We inoculated affected tissue onto HE medium, and found that fungal isolates arising from this inoculum are identical to SA-25. We did not find this isolate in 'control' areas, which included inoculated areas with the HE medium on which the isolate was grown, a different fungal isolate (from a diseased Trinidad sample), and a mock inoculation with a sterile loop (to check for injury).

We demonstrated that the disease is transmissible in San Salvador, Bahamas by removing diseased tissue from infected sea fans and inserting it into cuts made on healthy stands. We compared carbon source utilization patterns ${ }^{7,8}$ among the disease isolates SA-25, SS-7, seven reference strains (each a different species of Aspergillus) and two reference species of Penicillium. Based on these patterns, we found that the sea-fan isolates are more similar to each other than to the Aspergillus species. Nucleotide sequence analysis of the $18 \mathrm{~S}$ ribosomal RNA gene confirms that the isolate, SA-25, is more similar to Aspergillus fumigatis than to any other species available in the GenBank database. Sequences showed, however, only $96 \%$ identity.

Thus, morphological, physiological and nucleotide-sequence data all indicate that the putative pathogen falls within the genus Aspergillus and is likely to represent a new species. Aspergillus is not a common marine fungus, but it is a typical soil inhabitant. It generally does not sporulate in aqueous environments. Similarly, our isolates did not sporulate when covered with sterile artificial sea water and we saw only hyphae (no spores) in diseased rind tissue. This indicates that the primary infection occurs by hyphae, perhaps associated with sediment particles. Persistent mortality, then, would require a continuous source of infection. This situation would exist in areas receiving increased sedimentation loads due to the loss of forested lands ${ }^{2}$.

\section{Garriet W. Smith}

Lisa D. Ives

Biology Department,

University of South Carolina at Aiken,

South Carolina 29801, USA

Ivan A. Nagelkerken

Carmabi Foundation/Curaçao

Underwater Park,

PO Box 2090, Piscaderabaai $z / n$,

Curaçao, Netherlands Antilles

Kim B. Ritchie

Biology Department,

University of North Carolina,

Chapel Hill,

North Carolina 29599-3280, USA

1. Guzmán, H. M. \& Cortés, J. Rev. Biol. Trop. 32 , 305-308 (1984)

2. Garzón-Ferreira, J. \& Zea, S. Bull. Mar. Sci. 50, 522-526 (1992).

3. Peters, E. C. in Pathobiology of Marine and Estuarine Organisms (eds Couch, J. A. \& Fournie, J. W.) 393-437 (CRC, Boca Raton, 1993).

4. Nagelkerken, I. et al. in Proc. 8th Int. Coral Reef Symp. (eds Lessios, H. A. \& Macintyre, I. G.) (STRI, Panama City, in the press)

5. Rützler, K. \& Santavy, D. Mar. Ecol. 4, 301-319 (1983). 6. Moore-Landecker, E. Fundamentals of the Fungi 4th edn (Prentice-Hall, Upper Saddle River, New Jersey, 1996).

7. Bochner, B. R. Nature 339, 157-158 (1989).

8. Ritchie, K. B. \& Smith, G. W. Mol. Mar. Biol. Biotechnol. 4, 345-352 (1995)

\section{Vesicle assembly in microtubes}

SIR - Cytomimetic microstructures are attracting much attention ${ }^{1}$, with most studies being focused on spherical structures such as vesicles and liposomes ${ }^{2}$. Here we report the non-covalent self-assembly of vesicles encapsulated by microtubular structures made up of synthetic oligoglycine-based bola-amphiphiles.

The bola-amphiphiles $\mathrm{C}(n)\left[\mathrm{G}_{m}\right]_{2}(n=6$ and $10, m=2$ and 3; Fig. $1 a$ ) are dicarboxamides with two oligoglycine head groups at each end. They form white solids (melting points $>210^{\circ} \mathrm{C}$ ) with very low solubility in water, whereas the sodium salts are very soluble $(\leqslant 15 \mathrm{mM})$. If an aqueous solution (concentration $10 \mathrm{mM}, \mathrm{pH} 7 \sim 8$ ) is kept continuously at room temperature for 2-3 weeks, bola-amphiphiles form very thin fibrous assemblies. Phase-contrast microscopy of $\mathrm{C}(10)\left[\mathrm{G}_{3}\right]_{2}$ reveals welldefined tube-like fibre structures with a uniform diameter (about 1-2 $\mu \mathrm{m}$ ), containing many vesicular assemblies (Fig. $1 a)$. The spheres we observe strongly suggest the existence of multilamellar vesicles $^{3}$. The fibres are not worm-like tubules 